\title{
Oxygen-regulated protein-150 prevents calcium homeostasis deregulation and apoptosis induced by oxidized LDL in vascular cells
}

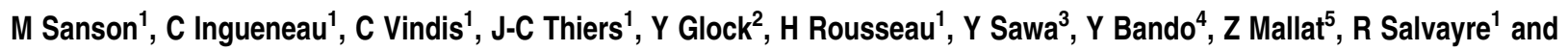 \\ A Nègre-Salvayre ${ }^{\star, 1}$
}

Oxidized LDLs (oxLDLs) induce apoptosis, which contributes to the pathogenesis of atherosclerosis. The $150 \mathrm{kDa}$ oxygenregulated protein (ORP150), an endoplasmic reticulum (ER)-resident chaperone, is upregulated by hypoxia and prevents ischemia-induced cell death. The aim of this work was to investigate whether and how ORP150 can prevent apoptosis induced by oxLDLs in vascular cells. OxLDLs induced ORP150 expression in the ER of human microvascular endothelial cell line (HMEC-1). ORP150 expression was blocked by antioxidants, by the permeant calcium chelator BAPTA-AM, and by inhibitors of the inositol1,4,5 trisphosphate (IP3) receptors, 2-aminoethyl diphenylborinate (2-APB) and xestospongin C. ORP150 silencing by siRNAenhanced oxLDL-induced apoptosis, while forced ORP150 expression increased the resistance of cells via an inhibition of the oxLDL-induced calcium rise, and of subsequent calpain activation, cytochrome $c$ release, caspase 3 activation and apoptosis. A similar protective effect was achieved by BAPTA-AM, 2-APB and xestospongin C. Altogether, these data indicate that (i)ORP150 inhibits oxLDL-induced apoptosis by blocking calcium signaling and subsequent apoptosis, (ii)calcium released from ER stores through IP3 channels is involved in the oxLDL-induced calcium rise and apoptosis, and is inhibited by ORP150. Finally, ORP150 is expressed in advanced atherosclerotic lesions, where it may locally participate to reduce the apoptotic effect of oxLDLs and the subsequent risk of plaque rupture.

Cell Death and Differentiation (2008) 15, 1255-1265; doi:10.1038/cdd.2008.36; published online 11 April 2008

Atherosclerosis is characterized by endothelial dysfunction and injury, lipid deposition, chronic inflammatory response, arterial wall and chronic wound healing processes. ${ }^{1,2}$ Apoptosis is potentially implicated in endothelial cell lining defects, necrotic core formation, plaque erosion and rupture. ${ }^{3,4}$ Among several pro-apoptotic factors present in atherosclerotic plaques, oxidized low-density lipoproteins (oxLDLs) play a crucial role in the formation and the progression of lesions, by triggering lipid storage, local inflammation and toxic events that may participate in vascular wall injury, plaque erosion/ rupture and subsequent athero-thrombosis. ${ }^{5,6}$ The proapoptotic effects of oxLDLs are mediated through a complex sequence of signaling events that lead to the activation of several caspase-dependent or -independent apoptotic pathways. $^{7-9}$ Two separate caspase-dependent apoptotic pathways have been implicated in the oxLDL-induced apoptosis of endothelial cells, namely the extrinsic apoptotic pathway, mediated by death receptors, Fas or/and tumor necrosis factor receptor, and downstream by caspase-8/ caspase-3; $;, 10,11$ and the intrinsic mitochondrial apoptotic pathway, which includes $\mathrm{Bcl}-2$ family members, cytochrome $c$ and caspase-3. ${ }^{12}$ The oxLDL-induced activation of the intrinsic mitochondrial pathway involves a sustained rise of cytosolic calcium that triggers a proteolytic cascade involving calcium-dependent calpains, Bid cleavage and cytochrome $c$ release, leading finally to caspase-3 activation. 8,13 The mechanism evoked by oxLDLs for triggering the cytosolic calcium rise is not known.

Among the various cytoprotective chaperones present in the endoplasmic reticulum (ER), the 150-kDa oxygenregulated protein (ORP150) is induced by ischemia/reperfusion and more generally by oxygen deprivation and oxidative stress. ${ }^{14}$ ORP150 exhibits antiapoptotic and neurotrophic properties that play a protective role in a range of settings, including apoptosis associated to ischemia ${ }^{15-18}$ excitotoxicity, ${ }^{19}$ neuron and cardiomyocyte cell death. ${ }^{20,21}$ ORP150 has

\footnotetext{
${ }^{1}$ Inserm U-858, Faculty of Medicine Rangueil, University Toulouse-3, CHU Toulouse, France; ${ }^{2}$ Department of Cardiovascular Surgery, Faculty of Medicine Rangueil, CHU Toulouse, France; ${ }^{3}$ Division of Cardiovascular Surgery, Department of Surgery, Osaka University Graduate School of Medicine, 2-2 Yamadaoka, Suita, Osaka 5650871, Japan; ${ }^{4}$ Department of Functional Anatomy and Neuroscience, Asahikawa Medical College, Asahikawa, Hokkaido, Japan and ${ }^{5}$ Inserm U689, Centre de Recherche Cardiovasculaire Lariboisière, Paris, France

${ }^{*}$ Corresponding author: A Nègre-Salvayre, Department of Biochemistry, INSERM U858, Eq10, IFR-31, CHU Rangueil, 1 avenue Jean Poulhès, BP84225 31432 Toulouse Cedex 4, France. Tel: + 335613227 05; Fax: + 335613220 84; E-mail: anesalv@ toulouse.inserm.fr or salvayre@ toulouse.inserm.fr Keywords: apoptosis; ORP150; oxidized LDL; endothelial cell; calcium

Abbreviations: oxLDL, oxidized low-density lipoprotein; ORP150, oxygen-regulated protein $150 \mathrm{kDa}$; ER, endoplasmic reticulum; HMEC-1, human microvascular endothelial cell-1; ev-HMEC, empty vector-transfected HMEC-1; ORP-HMEC, ORP150-transfected HMEC-1; wt-HMEC, wild type HMEC-1; hSMC, human smooth muscle cells (primoculture); BAPTA/AM, 1,2-bis-(0-Aminophenoxy)-ethane- $N, N, N, N$-tetraacetic acid, tetraacetoxy methyl ester; GRP78, glucose-regulated protein $78 \mathrm{kDa}$; PDTC, pyrrolidine dithiocarbamate; NAC, $N$-acetylcysteine; ROS, reactive oxygen species; TUNEL, terminal deoxynucleotidyl transferase biotin-dUTP nick end labeling; PI, propidium iodide; IP3, inositol-1,4,5 trisphosphate; 2-APB, 2-Aminoethyl diphenylborinate; siRNA, small interfering RNA; scr siRNA, scramble siRNA; FCS, fetal calf serum
} 
been shown to be expressed in atherosclerotic plaques, and to be induced in blood mononuclear phagocytes by oxLDLs under hypoxic conditions. ${ }^{22,23}$ The precise role of ORP150 in oxLDLs signaling, and apoptosis, has never been investigated. This study was carried out to investigate whether and how ORP150 plays a role in oxLDL-induced apoptosis of vascular cells.

\section{Results}

OxLDLs enhance the expression of ORP150 in wt-HMEC and hSMC. Under basal conditions, western blot experiments showed detectable, but low levels of ORP150 in HMEC-1 and hSMC (Figure $1 \mathrm{a}$ and $\mathrm{b}$ ). As shown in Figure $1 \mathrm{a}$ and $\mathrm{b}$, oxLDLs $(100 \mu \mathrm{g}$ apoB/ml) induced a marked increase in ORP150 antigen, beginning at $5 \mathrm{~h}$ and reaching a maximum after $10 \mathrm{~h}$ of incubation. The induction of ORP150 began at low non-toxic concentrations of oxLDLs, just starting at $10 \mu \mathrm{g}$ apoB/ml of oxLDLs, which is far below the toxic concentration of oxLDLs (Figure 1c). It is noteworthy that in vascular cells grown under the reported culture conditions, oxLDLs were able to induce an increased expression of ORP150, without any additional hypoxia. Incubation of cells under the same conditions, but omitting LDL, did not induce ORP induction order, thus supporting the hypothesis of a specific effect of oxLDLs and excluding any interference of copper ions irradiated by UV (Figure 1a, right panel).

Immunofluorescence studies also showed that ORP150 (green fluorescence) was only faintly expressed in untreated HMEC-1 and colocalized in major part with ER-located proteins, such as GRP78/GRP94, labeled with an anti-KDEL antibody (red fluorescence) (Figure 1d, upper panels). In HMEC-1 treated with oxLDLs $(100 \mu \mathrm{g}$ apoB/ml) for $10 \mathrm{~h}$, ORP-150 localized in part in the ER (colocalization with anti-KDEL labeling - red), but it may be noted that the green immunofluorescence of ORP150 was also in part localized in the cytoplasm and at the plasma membrane (Figure 1d, lower panels).

Interestingly, oxLDL-induced ORP150 expression was reduced by antioxidants trolox, PDTC and $\mathrm{N}$-acetylcysteine (NAC), as well as by the calcium chelator BAPTA (Figure 1e and $\mathrm{f}$ ) (note that BAPTA was administered to the cells as permeant form BAPTA-AM which is cleaved by intracellular esterases thereby releasing the calcium chelator BAPTA in the cytoplasm). The role of calcium signaling as trigger of ORP150 expression induced by oxLDLs, was confirmed by the inhibitory effect of two inositol-1,4,5 trisphosphate (IP3) channel inhibitors, 2-Aminoethyl diphenylborinate (2-APB) and Xestospongin $C$, used under conditions inhibiting the early calcium peaks triggered by oxLDLs (Figure $1 \mathrm{~g}$ and $\mathrm{h}$ ).

Altogether these data indicate that ORP150 expression is induced by oxLDLs through a calcium and oxidative stress-mediated mechanism.

ORP150 silencing by siRNA enhances oxLDL-induced toxicity. Since ORP150 exhibits cytoprotective properties in hypoxia, in neurotoxicity ${ }^{15-20}$ and in hypoxia/oxLDL-induced toxicity to monocytes, ${ }^{23}$ we aimed to evaluate whether it may prevent oxLDL-induced apoptosis of vascular cells. Under the used conditions, ORP150 specific siRNA abolished the upregulation of ORP150 induced by oxLDLs, in hSMC and wt-HMEC (Figure 2a), and enhanced the toxic effect of oxLDLs (Figure 2b), whereas scrambled siRNA had no effect. We evaluated the effect of ORP150 depletion on the type of cell death, by using a fluorescent (Apostain ${ }^{\mathbb{R}}$ ) method based on the increased sensitivity of DNA in apoptotic cells to thermal denaturation and immunofluorescence detection of single strand DNA (Figure 2c) and by SYTO 13/PI twotone fluorescent staining of DNA that allows discriminating between alive cells, and dead cells in apoptosis, postapoptotic necrosis and primary necrosis (Figure 2d). Interestingly, no toxicity was observed in the presence of ORP150-siRNA used alone (i.e. in the absence of oxLDLs), thus suggesting that ORP150 is not required for cell survival under standard culture conditions (Figure $2 \mathrm{e}$ and $\mathrm{f}$ ). In contrast, oxLDL-treatment of cells treated by ORP150siRNA, resulted in a dramatic increase of both apoptotic and necrotic cells (Figure $2 e$ and $f$ ), thus suggesting that ORP150 is involved in cellular defenses against the toxicity of oxLDLs.

ORP150 expression prevents oxLDL-induced apoptosis. To confirm the protective effect of ORP150 against the toxicity of oxLDLs, we examined the effect of ORP150 overexpression on oxLDL-induced toxicity. We used a clone of ORP-HMEC expressing ORP150 approximately seven times more than the wt-HMEC (Figure $3 a$ and b). Under standard culture conditions, ORP-HMEC (compared to wt-HMEC and to ev-HMEC) did not exhibit any difference in cell growth and cell viability (Figure 3c). OxLDLs $(200 \mu \mathrm{g}$ apoB/ml) were similarly toxic for wt-HMEC and ev-HMEC, but significantly less toxic for ORP-HMEC (Figure 3c), thereby supporting the hypothesis that ORP150 prevents the toxic effect of oxLDLs. In the same way, SYTO13/PI fluorescent labeling showed that ORP150 overexpression prevented oxLDL-induced apoptosis (Figure 3d and e).

Interestingly, in our experimental model system, ORP150 also prevented in part, the calcium-dependent toxicity of thapsigargin (Figure $3 c$ ), like in cultured neuronal cells. ${ }^{20}$ These data led us to investigate whether ORP150 was able to block the calcium signaling involved in oxLDL-induced apoptosis.

ORP150 expression inhibits the rise of cytosolic calcium, calpain activation and the mitochondrial apoptotic pathway triggered by oxLDLs. We previously reported that oxLDL-induced apoptosis results from the dysregulation of the cytosolic calcium homeostasis, characterized by a delayed and intense calcium rise occurring several hours after the beginning of the pulse with oxLDLs. ${ }^{7}$ As the calcium rise induces the activation of calcium-dependent calpains, which activate in turn the mitochondrial apoptotic pathway, ${ }^{8,13}$ we investigated whether ORP150 forced expression was able to prevent the apoptotic signaling cascade. As shown in Figure $4 \mathrm{a}$, the broad, intense and delayed (9-16 h) rise of cytosolic calcium triggered by oxLDLs was considerably reduced in 
a

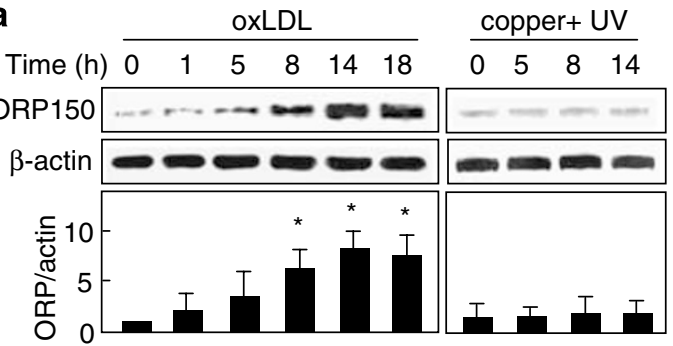

b

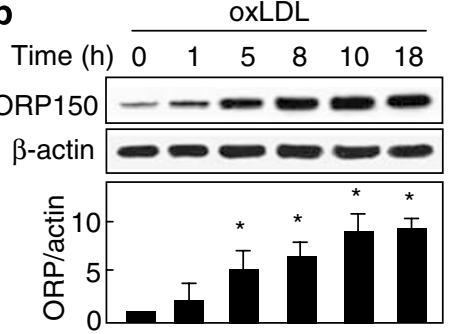

C

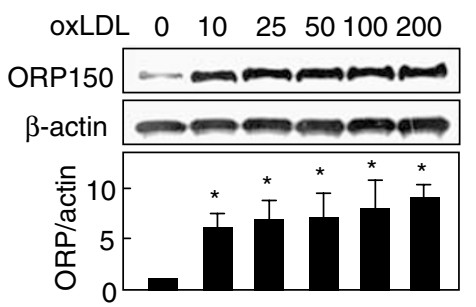

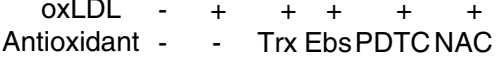

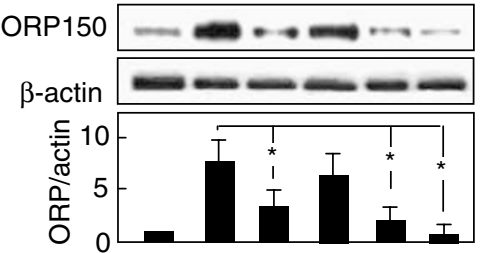

g

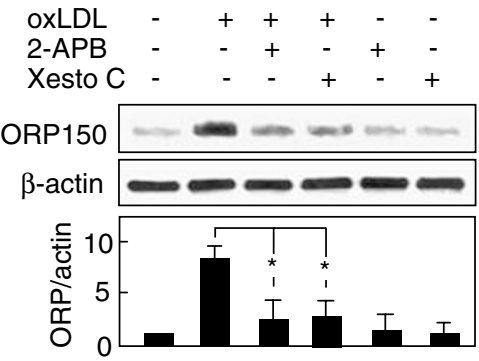

d

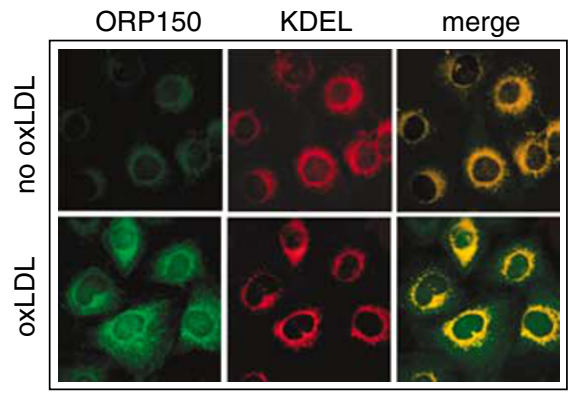

f

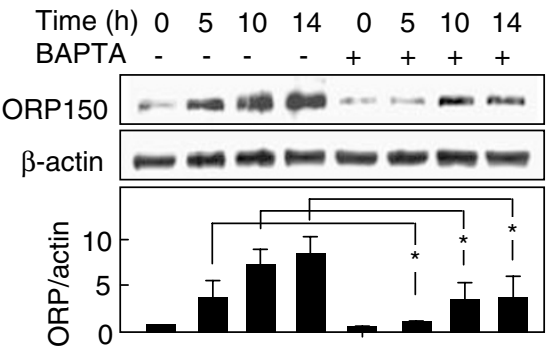

$\mathbf{h}$

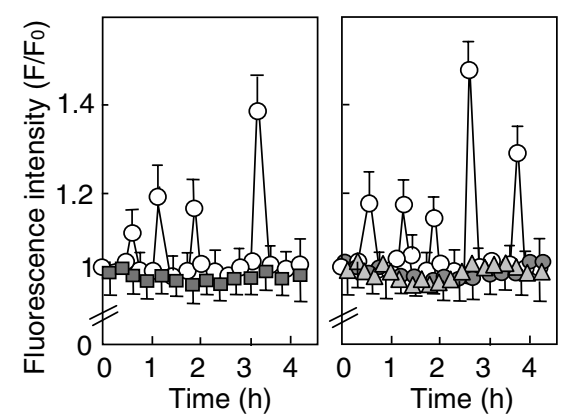

Figure 1 Upregulation of ORP150 by oxLDLs in HMEC-1 (a, C-H) and hSMC (b) and inhibition by antioxidants, BAPTA and IP 3 channel inhibitors. (a, b) Time course of ORP150 expression induced by oxLDLs (100 $\mu \mathrm{g}$ apoB/ml) in wt-HMEC (a) and in hSMC (b). In A, right panel, control experiment: wt-HMEC were incubated for the indicated time with the dialysis buffer supplemented with $5 \mu \mathrm{M}$ CuSO4 and UV-irradiated, under the same conditions as oxLDL preparation, but omitting LDL. (c) Expression of ORP150 in wt-HMEC incubated for $14 \mathrm{~h}$ with increasing concentrations of OxLDLs. (d) Immunofluorescence microscopy of ORP150 and KDEL proteins (located in the endoplasmic reticulum) of wt-HMEC treated or not with oxLDLs $(100 \mu \mathrm{g} a \mathrm{apoB} / \mathrm{ml})$. (e-g) Inhibitory effect of antioxidants (e), BAPTA (f) and IP3 channel inhibitors (g) on ORP150 upregulation induced by oxLDLs $(100 \mu \mathrm{g}$ apoB/ml). wt-HMEC were preincubated for $30 \mathrm{~min}$ with antioxidants, $100 \mu \mathrm{mol} / \mathrm{l}$ of trolox (Tx), ebselen (Ebs) or PDTC, NAC 20 mmol/ I, BAPTA (used at $1 \mu \mathrm{mol} / / \mathrm{BAPTA} / \mathrm{AM}), 2-\mathrm{APB}(10 \mu \mathrm{M})$ and xestospongin $\mathrm{C}$ (xesto) $(1 \mu \mathrm{M})$, then oxLDLs $(100 \mu \mathrm{g}$ apoB/ml) were added to the culture medium. Cells were harvested at the indicated time (or at $10 \mathrm{~h}$, when not indicated) and used for western blots as indicated in Material and Methods. (h) Early calcium peaks triggered by oxLDLs $(100 \mu \mathrm{g} \mathrm{apoB} / \mathrm{ml})$, in the absence (empty circles) or presence of calcium inhibitors (BAPTA, blue squares; 2-APB, red circles; xestospongin C, green triangles), used under experimental conditions of Figure 1e and g. Calcium mobilization was determined at the indicated times, using Fluo3-AM and under the conditions reported in experimental section. The fluorescence of fluo3 is normalized by proteins and the results are expressed as ratio F/FO (F0 is the fluorescence intensity of the unstimulated control). Note the relative variability of the peaks depending on cell and oxLDLs batches. Data are expressed as mean \pm S.E.M. of $n=3-5$ separate experiments $\left({ }^{*} P<0.05\right)$. Western blot and immunofluorescence microscopy shown here are representative experiments

ORP-HMEC. Similarly, the oxLDL-induced calcium signaling occurring between 0 and $4 \mathrm{~h}$ was inhibited in ORP-HMEC (Figure 4b). Calcium imaging by fluorescence microscopy visualized the intense calcium signal in wt-HMEC cells treated by oxLDLs, whereas the fluorescence intensity was very low in ORP-HMEC treated under the same conditions (Figure 4c). Interestingly, in ORP-HMEC, the calcium rise triggered by thapsigargin was lower than that in wt-HMEC 
a

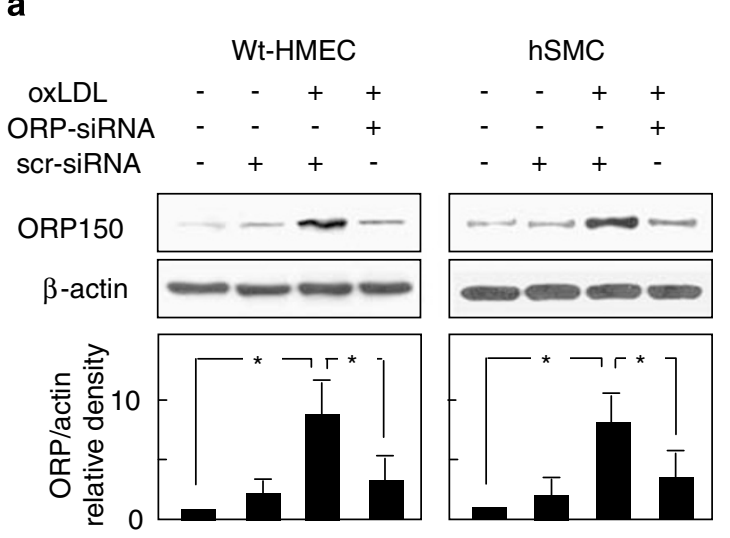

C

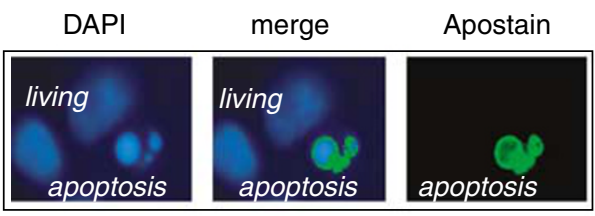

e

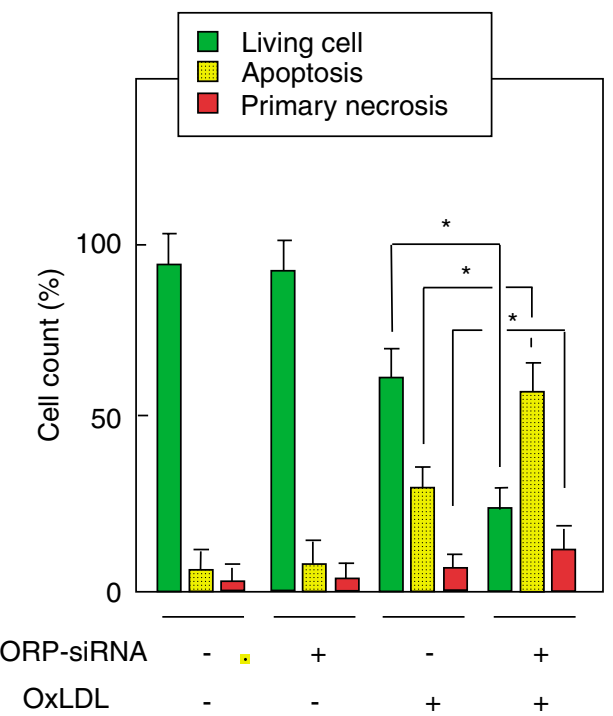

b

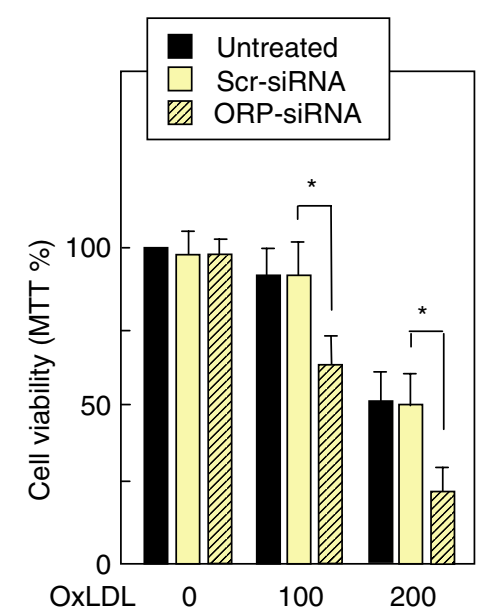

d

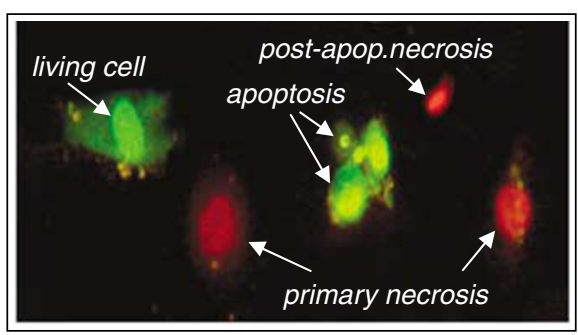

f
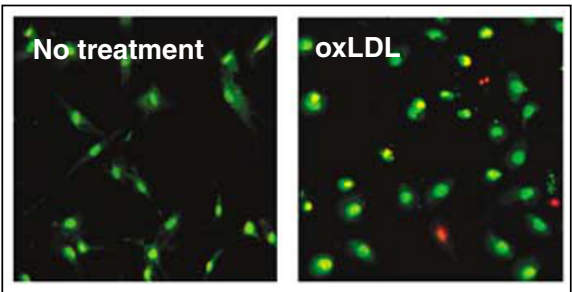

\section{ORP-SIRNA}
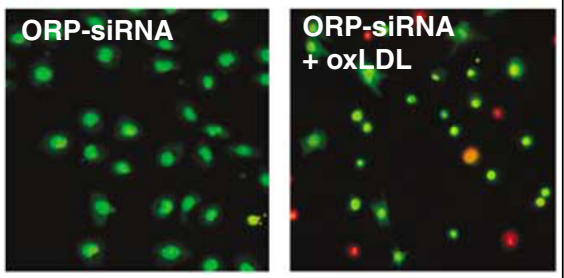

Figure 2 Down regulation of ORP150 by siRNA enhances oxLDL-induced apoptosis. (a) Western blot showing ORP150 expression in wt-HMEC and hSMC pretreated with ORP150-specific siRNA or scr-siRNA for $48 \mathrm{~h}$, then incubated without or with oxLDLs (100 $\mu \mathrm{g} / \mathrm{ml}$ for $14 \mathrm{~h}$ ). (b) Toxicity of oxLDLs in wt-HMEC transfected with ORP150 specific siRNA or scr-siRNA for $48 \mathrm{~h}$, then incubated with oxLDLs (100 or $200 \mu \mathrm{g} / \mathrm{ml})$ for an additional $18 \mathrm{~h}$. The toxicity was evaluated by the MTT assay. (c, d) Fluorescence microscopy of apoptotic wt-HMEC visualized by fluorescent TUNEL (c) or staining by Syto-13/PI (D). (e, f) Cell death characterization in hSMC treated by ORP150-specific siRNA for $48 \mathrm{~h}$ and incubated with oxLDLs, then stained by syto13/IP and counted as in (b). In (a, b, $\mathbf{c}$ and $\mathbf{e})$, the data are expressed as mean \pm S.E.M. of five separate experiments $\left({ }^{*} P<0.05\right)$, and in $(\mathbf{c}, \mathbf{d}, \mathbf{f})$ representative of these experiments

(Figure 4d), thus pointing out the ability of ORP150 to maintain calcium homeostasis, in agreement with Kitao et al. ${ }^{19}$ The apoptotic cascade resulting from the delayed calcium rise was activated in wt-HMEC, as shown by calpain activation, (Figure 4e), the release of cytochrome $c$ in the cytosol (Figure 4f), and the activation of caspase 3 evidenced by the cleavage of procaspase- 3 in wt-HMEC (Figure $4 \mathrm{~g}$ ), and by the hydrolysis of the cell-permeant fluorescent pancaspase substrate FLICA (Figure 4h). In contrast, no increase in the different apoptosis parameters was observed in ORP-HMEC. Same results were observed when loading the cells with BAPTA, which prevented the cytosolic calcium rise, the activation of calpain, and oxLDL-induced cytotoxicity (Figures 4 and 5), in agreement with data obtained on other 
a

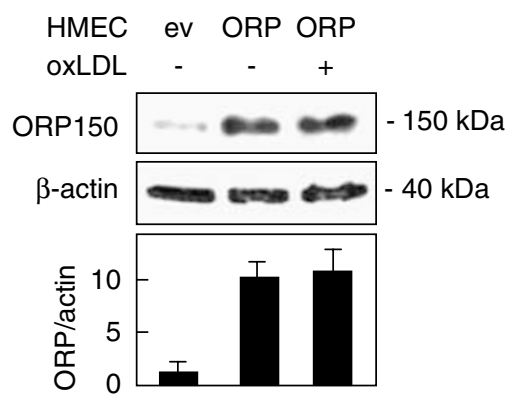

b

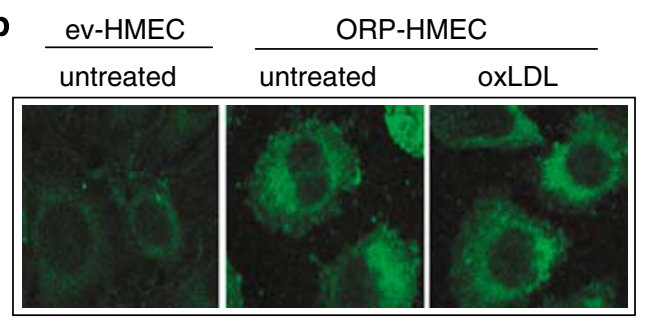

d
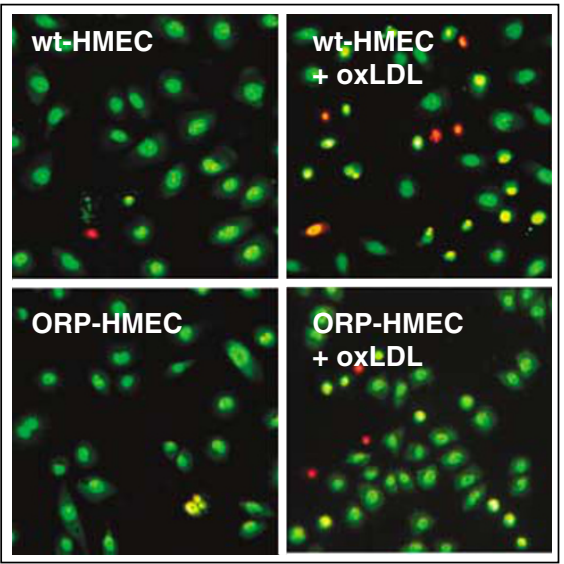
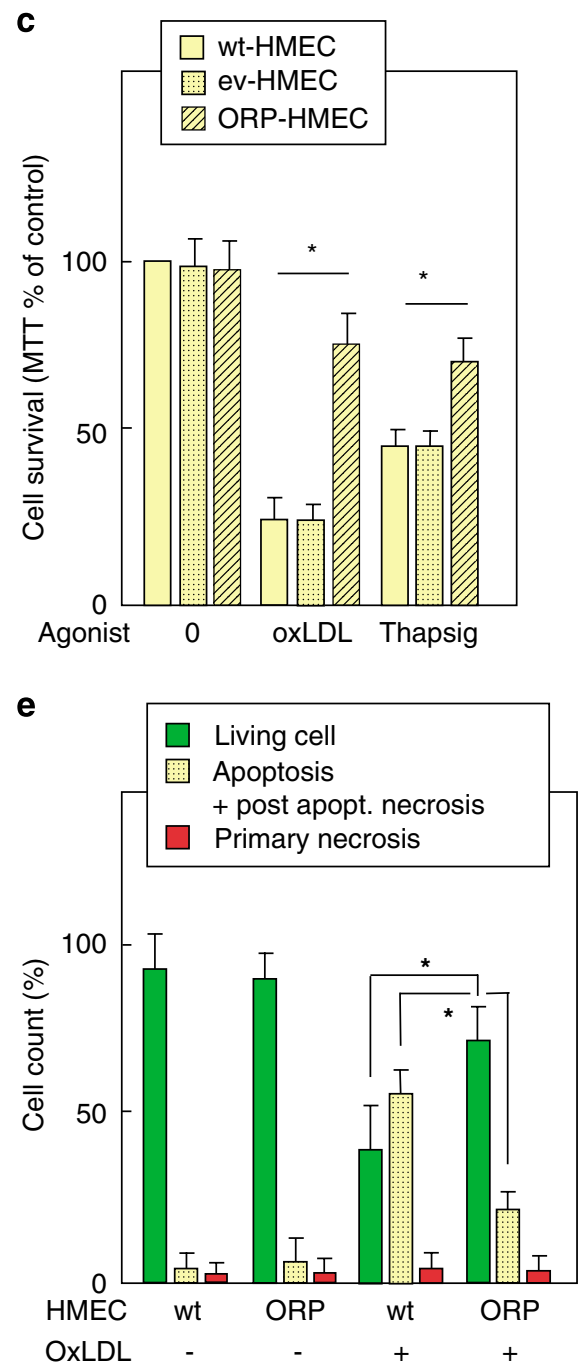

Figure 3 ORP150 expression enhances cell resistance to oxLDL-induced apoptosis. ORP-HMEC and ev-HMEC were obtained by stable transfection of wt-HMEC under the conditions reported in the experimental section. (a, b) Western blot (a) and immunofluorescence microscopy of ORP150 in ev-HMEC and in ORP-HMEC, incubated with or without oxLDLs (200 $\mu \mathrm{g} / \mathrm{ml}$ for $14 \mathrm{~h}$ ). (c) Relative resistance of wt-HMEC, ev-HMEC and ORP-HMEC to the toxic effect of oxLDLs (200 $\mu \mathrm{g} / \mathrm{ml})$, and thapsigargin (Thapsig, $1 \mu \mathrm{M})$ for $24 \mathrm{~h}$, evaluated by the MTT assay. (d) Apoptosis and necrosis induced by oxLDLs ( $200 \mu \mathrm{g} / \mathrm{ml}$ for $24 \mathrm{~h})$ in wt-HMEC and ORP-HMEC, stained with syto13/PI DNA probes. (e) Evaluation of living, apoptotic and necrotic wt-HMEC incubated with oxLDLs (200 $\mu \mathrm{g} / \mathrm{ml}$ for $18 \mathrm{~h}$ ) and labeled with fluorescent DNA probes as in (d). In (c and $\mathbf{e})$, the data are mean \pm S.E.M. of five separate experiments $\left({ }^{*} P<0.05\right)$

cell types. ${ }^{8,13,24}$ These data suggest that ORP150 overexpression inhibits the oxLDL-induced deregulation of calcium homeostasis and its subsequent apoptotic events.

We hypothesized that ORP150 could prevent the cytosolic calcium deregulation, by inhibiting the release of calcium from ER stores, as suggested by the inhibition of oxLDL-induced early and transient calcium peaks in ORP-HMEC (Figure 4b). To test whether calcium released from ER may play a role in apoptosis ${ }^{25}$ we evaluated the effect of Xestospongin $\mathrm{C}$, and 2APB, two inhibitors of the inositol-1,4,5 trisphosphate (IP3) receptors, on oxLDL-induced calcium deregulation and proapoptotic signaling. As shown in Figure 5, both agents blocked the delayed cytosolic calcium increase, calpain activation, and the cytotoxicity of oxLDLs. These data indicate that (i) $\mathrm{IP}_{3}$ receptors and calcium from internal ER stores are important mediators of the oxLDL-induced calcium deregulation and apoptosis, and (ii) ORP150, localized in $E R$, could inhibit the calcium release from ER, which in turn protects against the cytosolic calcium deregulation and subsequent apoptosis evoked by oxLDLs in endothelial cells.

ORP150 expression in atherosclerotic plaques from human carotid. ORP150 was highly expressed in advanced atherosclerotic plaques from human carotids, whereas it was only very faintly expressed in nonatherosclerostic areas, as shown by western blot of tissue homogenates (Figure 6a). Immunohistochemical analysis revealed that ORP150 is expressed in the macrophagic cells of the lipid-rich core, as previously reported by Tsukamoto $Y$ et $a l^{23}$ but was also strongly expressed in endothelial cells (Figure 6b), consistent with the oxLDL-induced upregulation of ORP150 in cultured endothelial cells. 


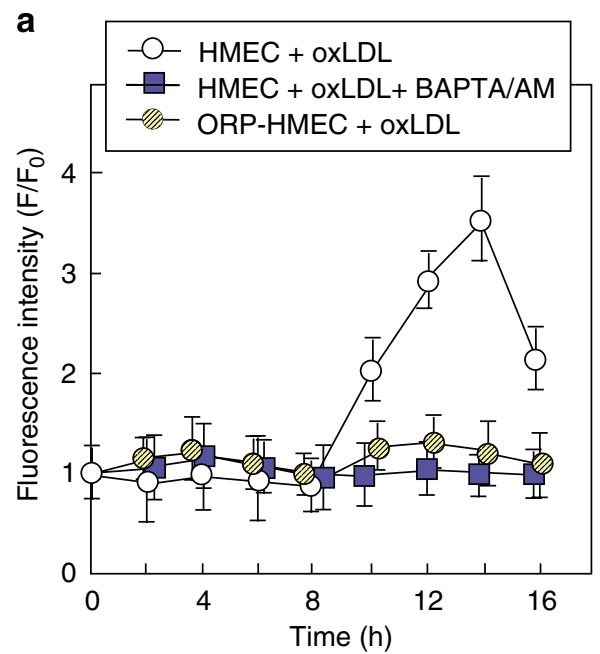

b

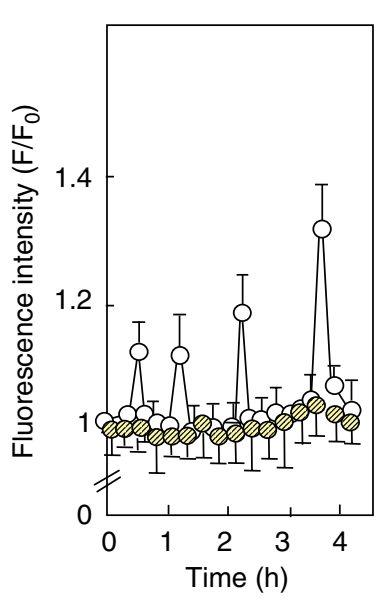

c
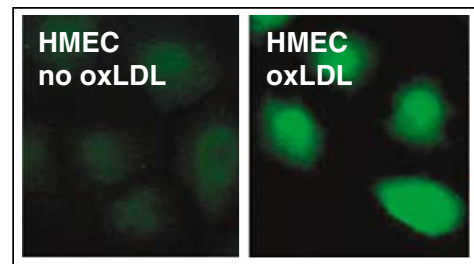

ORP-HMEC

ORP-HMEC no oxLDL
oxLDL d

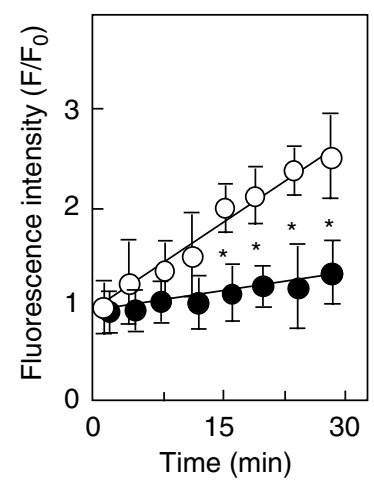

g

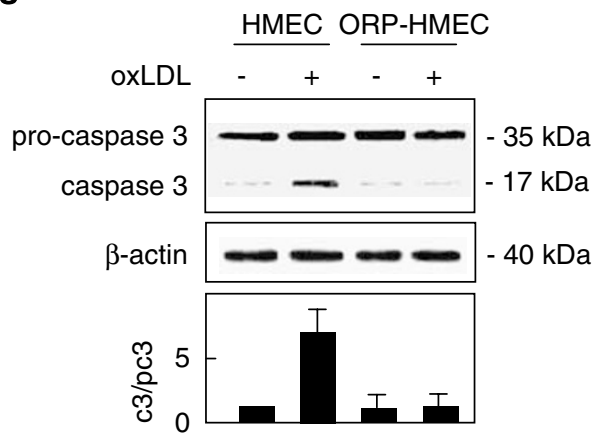

e

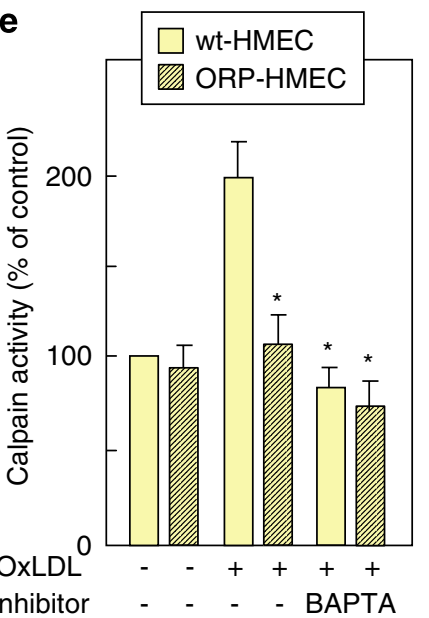

f

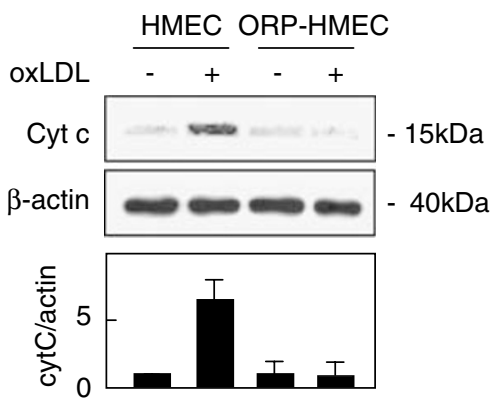

h
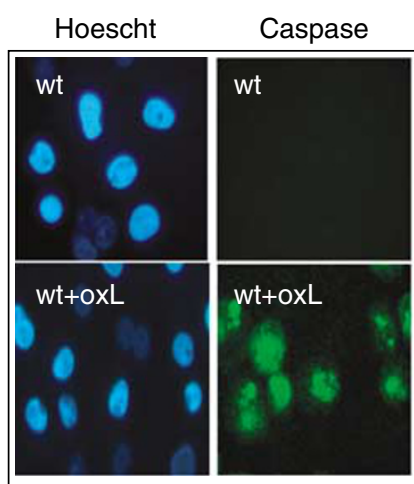

Hoescht

Caspase

ORP

ORP $+\mathrm{OxL}$

ORP

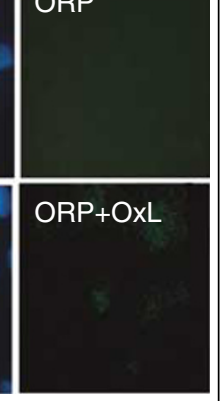

Figure 4 ORP150 expression prevents calcium deregulation and subsequent pro-apoptotic events, such as calpain activation, cytochrome $c$ release and caspase activation. (a, b) Time course of delayed (a) and early (b) cytosolic calcium rises induced by oxLDLs ( $200 \mu \mathrm{g}$ apoB/ml) in wt-HMEC and ORP-HMEC. Calcium mobilization was determined at the indicated time, under standard conditions reported in experimental section and in the legend to Figure 1. Mean \pm S.E.M. of six separate experiments. (c) Fluorescence microscopy of wt-HMEC and ORP-HMEC loaded with Fluo-3/AM as described in Material and Methods, and incubated for $14 \mathrm{~h}$ with or without oxLDLs (200 $\mu \mathrm{g}$ apoB/ml) under the conditions of 4A. (d) Time course of cytosolic calcium rise induced by thapsigargin ( $1 \mu \mathrm{M})$, in wt-HMEC and ORP-HMEC. Mean \pm S.E.M. of four separate experiments. (e) Calpain activity of wt-HMEC and ORP-HMEC treated with oxLDLs $(200 \mu \mathrm{g}$ apoB/ml, for $16 \mathrm{~h})$ and, when indicated, with BAPTA (under the conditions of Figure 4a). Enzyme activity is expressed as $\% \pm$ S.E.M. $\left({ }^{*} P<0.01\right)$, of the basal calpain activity measured in unstimulated cells. (f) Western blot of cytochrome $c$ released in the cytosol from wt-HMEC and ORP-HMEC incubated with oxLDLs $(200 \mu \mathrm{g} \mathrm{apoB} / \mathrm{ml})$ for $16 \mathrm{~h}$. (g) Western blot of both proform and active cleaved form of caspase 3 , in cell extracts from wt-HMEC and ORP-HMEC incubated with or without oxLDLs $(200 \mu \mathrm{g}$ apoB/ml) for $16 \mathrm{~h}$. (h) Determination of in situ caspase activation. Wt-HMEC and ORPHMEC were incubated with oxLDLs $(200 \mu \mathrm{g} / \mathrm{ml})$ for $16 \mathrm{~h}$. Then, cells were stained using the in situ caspase detection kit FLICA ${ }^{\mathrm{T}}$ : upper panels, control unstimulated wt-HMEC (Wt) and ORP-HMEC (ORP), lower panels, oxLDL-incubated cells (200 $\mu \mathrm{g}$ apoB/ml, $16 \mathrm{~h}$ ). Nuclei were stained by the fluorescent blue intercalating Hoechst (blue labeling) or with the green fluorescent pan-caspase substrate FAM-VAD-fmk (green labeling), revealing cells containing activated caspases 
a

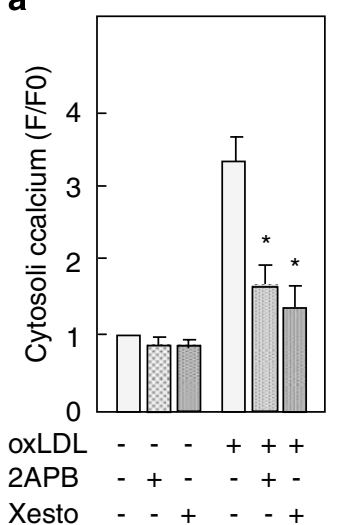

b

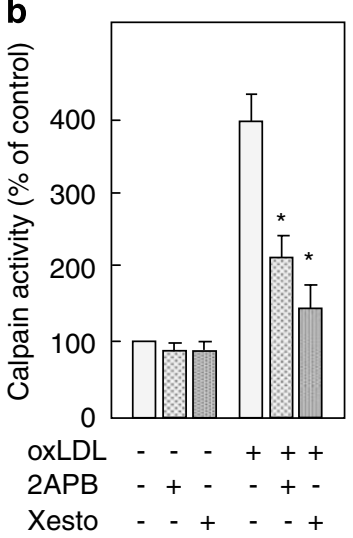

C

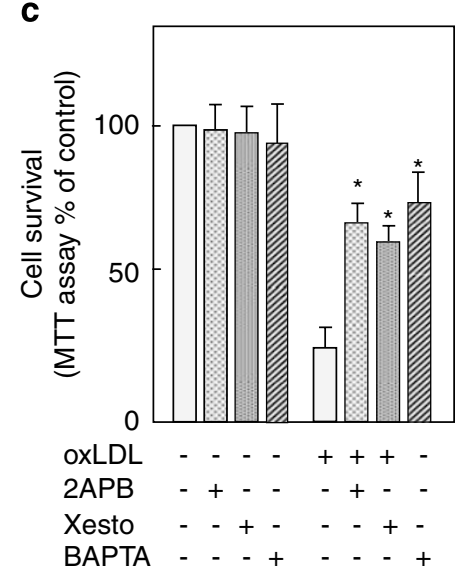

Figure 5 Effect of IP3 receptor inhibitors on oxLDL-mediated calcium increase and cytotoxicity in wt-HMEC. (a) Determination of the delayed (14 h) calcium increase induced by oxLDLs $(200 \mu \mathrm{g} / \mathrm{ml})$, in absence or in presence of 2-APB $(10 \mu \mathrm{M})$ or xestospongin C (xesto) $(1 \mu \mathrm{M})$. (b, c) Effect of IP3 receptor inhibitors on oxLDL-induced calpain activation and cell death evaluated by the MTT assay. These data are mean \pm S.E.M. of five separate experiments $\left({ }^{\star} P<0.05\right)$

\section{Discussion}

The major findings of this study are summarized as follows, (i) oxLDLs enhance the expression of ORP150 in cultured vascular endothelial and smooth muscle cells, depending on oxidative stress and $\mathrm{Ca}^{2+}$ release from ER stores (ii) ORP150 protects endothelial cells against oxLDL-induced apoptosis by blocking the deregulated and delayed cytosolic calcium rise, probably by inhibiting the release of calcium from ER stores, and (iii) ORP150 is dramatically expressed in endothelial cells of human advanced atherosclerotic plaques.

The basal expression of ORP150 is low in wt-HMEC and in hSMC grown under standard conditions. We show here, for the first time, that oxLDLs, independently of hypoxia, upregulate ORP150 expression in vascular cells. A previous study in macrophages showed that ORP150 induction required both hypoxia and oxLDLs, whereas oxLDLs under normoxic conditions did not enhance ORP150 expression. ${ }^{23}$ This discrepancy may result from differences in cell types, modification of oxLDLs, and culture conditions, particularly the concentration of fetal calf serum (FCS) in the culture medium (since low FCS is known to enhance the toxic effect of oxLDLs).

Our current results further demonstrate that induction of ORP150 by oxLDLs depends on oxidative stress, as indicated by the inhibitory effect of antioxidants Trolox, PDTC and NAC, consistently with previous reports. ${ }^{21,23}$ Furthermore, our data show that $\mathrm{Ca}^{2+}$-mobilization early evoked by oxLDLs, and blocked by the calcium chelator BAPTA and by $\mathrm{IP}_{3}$ channel inhibitors 2-APB and xestospongin $\mathrm{C}$, is also involved in the expression of ORP150, in agreement with previous reports on celecoxib-induced ORP150 upregulation ${ }^{26}$ (inhibited by BAPTA). The early $\mathrm{Ca}^{2+}$ mobilization evoked by oxLDLs has been reported in various cell types including macrophages, smooth muscle cells and platelets. ${ }^{24,27}$ Though the mechanism is not yet clarified, this calcium mobilization could result from oxLDL-mediated signaling, which includes the activation of various kinases, protein $G$, tyrosine kinase receptors and phospholipases, largely reported in the literature..$^{5,6}$ In the same way, it may be noted that oxLDLs triggered an ER stress response (data not shown) concomitantly with ORP150 induction, but the precise mechanisms of the regulation of ORP150 expression remain to be elucidated.

Silencing of ORP150 by specific siRNA dramatically enhanced the level of oxLDL-induced apoptosis in wt-HMEC. This is consistent with the observation that neural, myocardial, macrophagic or tumoral cells expressing low level of ORP150, induced by specific antisense, siRNA or in heterozygous deficient cells (ORP150+/-), exhibited an increased vulnerability to hypoxia, ischemia-reperfusion, glutamate or celecoxib. ${ }^{16,18,19,21,23,26,28}$

Conversely, the stable expression of ORP150 in ORP-HMEC enhanced significantly the cellular resistance to oxLDL-induced apoptosis. Interestingly, this is consistent with the protective effect of ORP150 against apoptosis induced by hypoxia in renal cells HEK16, cardiomyocytes ${ }^{21}$ and neural cells. $^{28}$ This suggests a common signaling in the apoptosis triggered by these toxic agents.

Toxic concentrations of oxLDLs evoke a delayed and sustained rise of cytosolic calcium, which is involved in the trigger of apoptosis of endothelial cells, as assessed by the protective effect of $\mathrm{EGTA}^{8}$ and of the permeant calcium chelator BAPTA, in agreement with previous data on other cell types. $^{7,8,13}$ This calcium rise is known to activate calciumdependent calpains, which trigger in turn the activation of mitochondrial apoptotic events (cytochrome $c$ release) and executioner caspase-3.8,13 Interestingly, calcium deregulation is also involved in ER stress-associated apoptosis induced in macrophages by free cholesterol accumulation $^{29,30}$ and in vascular SMC, by oxysterols, such as 7-ketocholesterol ${ }^{31}$ (which is abundantly present in oxLDLs). The precise mechanism leading to oxLDL-induced sustained calcium rise is only partly understood. Pharmacological inhibitors and the effect of EGTA suggest that an influx of extracellular calcium ${ }^{8,32}$ is required for oxLDL-induced sustained calcium and subsequent apoptosis. ${ }^{8,13}$ Our data indicate that the release of calcium from intracellular stores such as ER, is involved in the trigger of the cytosolic calcium rise, as supported by the inhibitory effect of IP3 channel inhibitors, 2-APB and xestospongin $\mathrm{C}$, on the calcium 
a
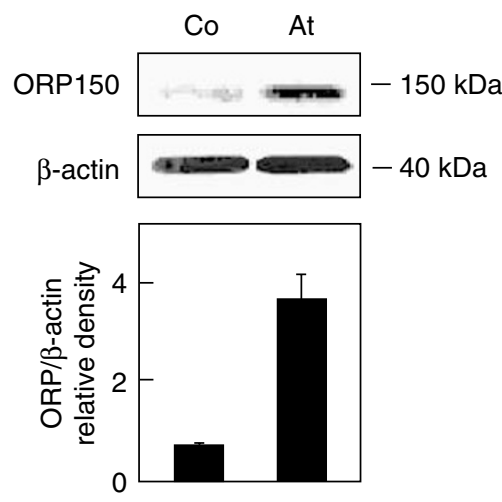

b Normal carotid wall
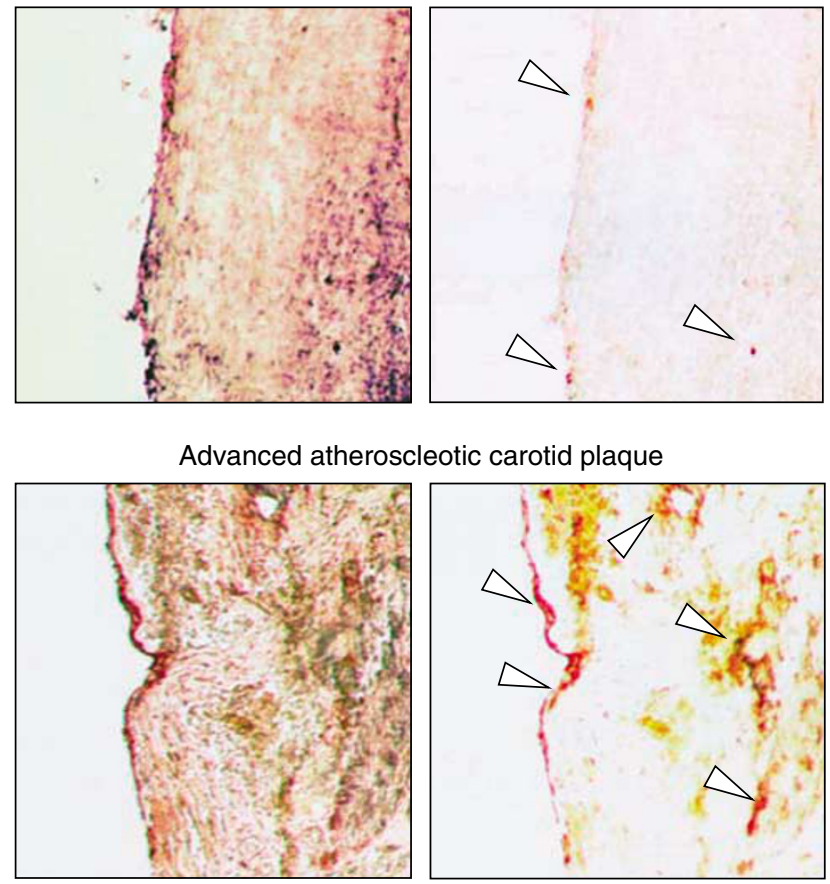

Figure 6 Expression of ORP150 in atherosclerotic lesions. (a) Detection of ORP150 in extracts from atherosclerotic (advanced plaque) and non atherosclerotic area from human carotid. Tissue extracts were used for western blots, revealed with anti-ORP150 and anti- $\beta$-actin. (b) Histology and immunohistochemistry of a non-atherosclerotic area (upper panels) and atherosclerotic lesion (lower panel). Left panels, hematoxylin-eosin staining; right panels, ORP150 expression detected by immunohistochemistry. It may be noted that ORP150 is expressed at much higher levels in atherosclerotic areas and is associated to the endothelium and to the lipid core (arrows). These data are representative of three separate experiments

increase and subsequent cell death. This is consistent with a role for calcium released from ER stores in apoptosis, which involves either IP3 receptors activation by IP3, or their direct cleavage by caspase- $3 .{ }^{33}$ The IP3-sensitive calcium store depletion may activate in turn plasma membrane receptors such as store-operated cation channels, calcium releaseactivated channels and transient receptor potential channels, thereby inducing an influx of extracellular calcium and apoptosis. $^{34}$

The overexpression of ORP150 prevented the boost in cytosolic calcium caused by oxLDLs, thereby preventing calcium-dependent calpain activation, cytochrome $c$ release and caspase 3 activation. These data are consistent with the protective effect of ORP150 against calcium-mediated toxicity, reported in various in vitro and in vivo conditions, including ischemia/reperfusion, ${ }^{21}$ glutamate toxicity $^{19}$ or treatment with Celecoxib. ${ }^{26}$ Our data point out the ability of ORP150 to maintain calcium homeostasis as a crucial mechanism of its protective effect against oxLDL-induced apoptosis, since the apoptotic events (activation of calpain and of the mitochondrial apoptotic pathway) were completely blocked. Interestingly, this capacity to regulate calcium homeostasis is shared by other ER-resident chaperones, such as GRP78 (Bip) and GRP94, which may prevent hypoxia-induced apoptosis by inhibiting intracellular calcium rise, calpain and caspase activation. ${ }^{35,36}$ It has also been reported that ORP150 may regulate calcium homeostasis by binding and buffering calcium, ${ }^{19,28}$ thereby limiting ER calcium depletion and cytosolic calcium rise. This binding effect could be due to the presence of calcium-binding sites on ORP150, comparable to those observed on CPB140, an ER protein homolog of ORP150, 
and able to bind $\mathrm{Ca} 2{ }^{+}{ }^{28,37}$ Moreover, it is not excluded that ORP150 may regulate the activity or interact with IP3 channels, like GRP $75,{ }^{38}$ in agreement with the protective effect of IP3 receptor inhibitors. As summarized in Figure 7, it can be speculated that ORP150 is induced by oxLDLs through an oxidative stress and $\mathrm{Ca}^{2+}$-dependent signaling, as a defence mechanism against oxLDL toxicity, and that ORP150-forced expression prevents apoptosis by blocking the dysregulation of calcium homeostasis, which is a general pathway for activating the intrinsic mitochondrial apoptotic pathway triggered by various toxic inducers, including oxLDLs. ${ }^{7,13,28}$

The last important point is the expression of ORP150 in the endothelium of human carotid atherosclerotic plaques, whereas it is only faintly expressed in non-atheromatous areas. The high expression of ORP150 in the endothelium covering atherosclerotic plaques is consistent with our data demonstrating that oxLDLs upregulate ORP150 expression in cultured endothelial cells, and with the well-known presence of oxLDLs in atherosclerotic lesions. ${ }^{1,39}$ This ORP150 expression may play a role in maintaining the integrity of the endothelial cell lining covering atherosclerotic plaques, by enhancing the resistance of endothelium against the toxic effect of underlying oxLDLs and their toxic oxidized lipid components.

\section{Materials and Methods}

Chemicals and reagents. Anti-ORP150 antiboby was obtained from IBL (Gunma, Japan), anti-procaspase3 was from Cell Signaling Technology, anticytochrome $c$ was from PharMingen, anti- $\beta$-actin was from Sigma-Aldrich, and secondary antibodies were obtained from Santa Cruz. 4',6-diamidino-2phenylindole (DAPI), acrylamide-4X/bisacrylamide-2X, 3-(4,5-dimethylthiazol-2-yl)2-5-diphenyl tetrazolium (MTT) were from Euromedex (Souffelweyersheim, Fr). SYTO-13, propidium iodide (PI), green and red Alexa Fluo secondary antibodies were from Molecular Probes. Trypsin-EDTA, culture media, FCS, glutamine, penicillin and streptomycin were provided from Gibco. Thapsigargin, 2-APB, xestospongin $\mathrm{C}$ and other reagents were from Sigma.

Cell culture and transfection by ORP150. Wt-HMEC (HMEC-1 cell line, CDC, Atlanta), were grown in MCDB-131 culture medium supplemented with $10 \%$ FCS and $40 \mu \mathrm{M}$ glutamine, $100 \mathrm{U} / \mathrm{ml}$ penicillin, $100 \mu \mathrm{g} / \mathrm{ml}$ streptomycin. HMEC-1 transfected with the ORP150-coding vector as reported in ${ }^{40}$ (ORP-HMEC), or with the empty vector (ev-HMEC), were grown in MCDB-131 medium supplemented with $0.8 \mu \mathrm{g} / \mathrm{ml}$ of geneticin (G418) (PAA laboratories). SMC primocultures (hSMC) were obtained from human coronary arteries at postmortem examinations. Briefly, $1-2 \mathrm{~mm}^{3}$ pieces of media from the coronary artery were cultured in DMEM containing $10 \%$ FCS, in T-25 flasks. Before use, hSMC were characterized by immunocytochemistry experiments using $\alpha$-actin labeling (data not shown), and were used between the second and third passage.

Twenty-four hours before the experiments, cells were starved by replacing the complete culture medium with serum-poor medium containing $0.5 \%$ FCS. Starving conditions have been defined in preliminary experiments, to balance between the anti-apoptotic effect of FCS and the pro-apoptotic effect of complete serum deprivation. Moreover, this serum-poor medium facilitates the uptake of oxidized $\mathrm{LDL}$, and minimizes the effect of potentially interfering mediators contained in FCS.

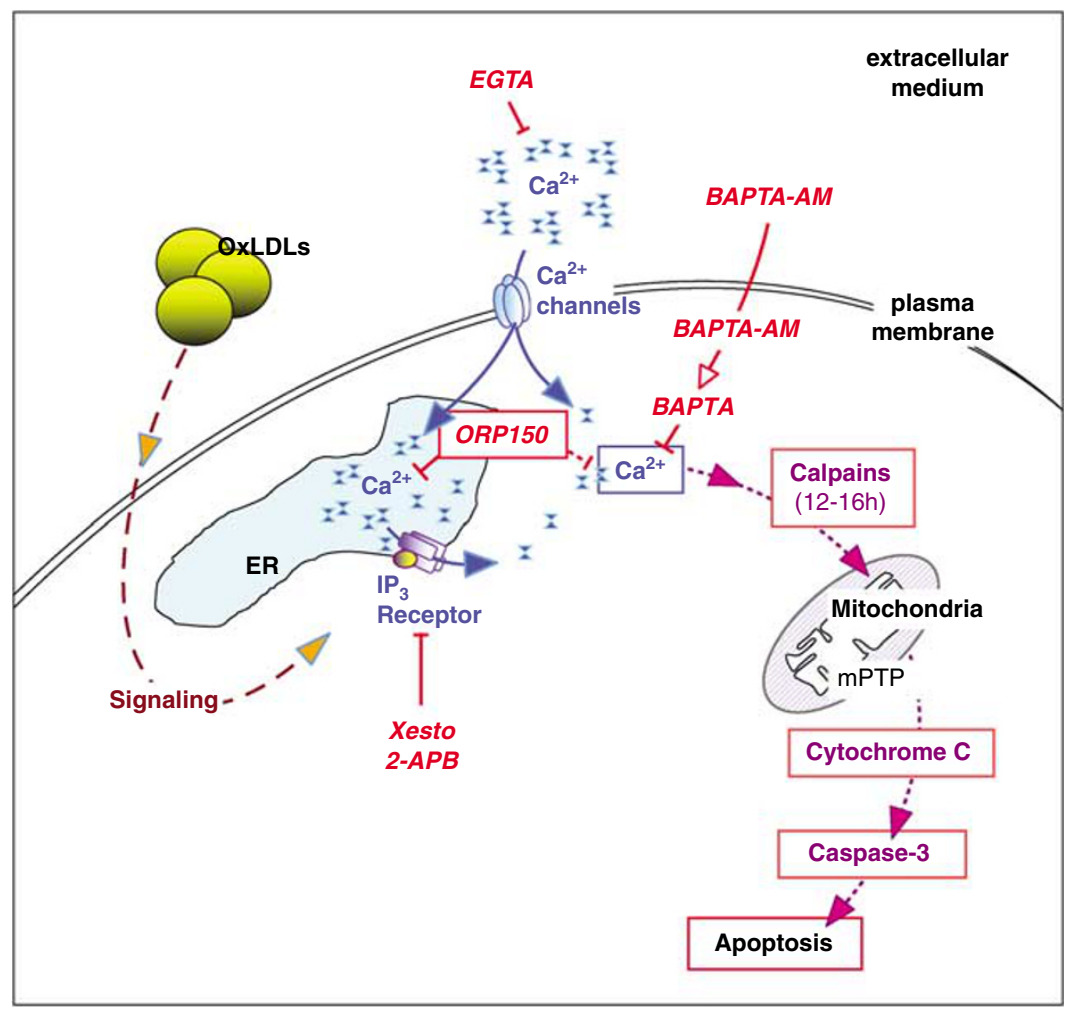

Figure 7 Schematic representation of oxLDL-induced calcium mobilization and apoptotic signaling, and protective effect of ORP150. OxLDLs trigger a complex, poorly defined, array of cell signaling ${ }^{5,6}$ including the opening of IP3-receptor/channel and the release of calcium from ER stores to the cytosol, and the opening of calcium channel located at the plasma membrane leading to massive calcium influx, as evidenced by the intense and sustained peak of cytosolic calcium. ${ }^{8,31}$ The calcium rise induces calpain activation, Bid cleavage and the activation of the mitochondrial apoptotic pathway ${ }^{8,13}$. Data reported here suggest that the ER chaperone ORP150 reduces the calcium release from ER stores, thereby preventing calcium-dependent calpain activation and subsequent activation of the mitochondrial apoptotic pathway 
ORP150 cloning and HMEC transfection by siRNA. Subconfluent wt-HMEC were transfected with $10 \mu \mathrm{g}$ of ORP 150 sense plasmid ${ }^{21}$ using $20 \mu \mathrm{l}$ of lipofectamine (Invitrogen), and cultured in the presence of $\mathrm{G} 418(1.5 \mathrm{mg} / \mathrm{ml})$ to select stable transfected HMEC clones, as reported. ${ }^{40}$

ORP150 siRNA (Eurogentec) were a pool of two sequences corresponding to part of the ORP150 sequence ( $5^{\prime}$-GCACAAUAAACGGGUACUC- $3^{\prime}$ and $5^{\prime}$-GCAU GGCGAUUAAGAAUCC- $\left.3^{\prime}\right)$. Control transfection was realized using a scrambled siRNA (scr-siRNA) sequence (Invitrogen). Cell transfection by siRNA was performed under the previously used conditions. ${ }^{40}$

LDL isolation and incorporation. LDLs from human pooled sera were prepared by ultracentrifugation and dialyzed against $\mathrm{NaCl} 0.15 \mathrm{M}$ phosphatebuffered saline (PBS) pH 7.3 containing $0.1 \mathrm{mM}$ EDTA. LDL were oxidized by UV irradiation ( $2 \mathrm{mg} \mathrm{apoB} / \mathrm{ml}$ in dialysis buffer supplemented with $5 \mu \mathrm{M}$ CuSO4), as previously reported. ${ }^{7}$ Under standard conditions, oxLDLs contained 71-104 nmol lipid hydroperoxide/mg apoB and 6.4-9.7 nmol TBARS/mg apoB. Note that (LDL free) dialysis buffer supplemented with $5 \mu \mathrm{M}$ CuSO4 and UV-irradiated under the same conditions as oxLDL preparation, was used as negative control.

Evaluation of cytotoxicity, necrosis and apoptosis. Cytotoxicity was evaluated using the MTT test. Alternatively, apoptotic and necrotic cells were counted after fluorescent staining of DNA by SYTO-13/PI $(0.6 \mu \mathrm{M}$ SYTO-13, a permeant DNA intercalating green-colored probe and $15 \mu \mathrm{M}$ propidium iodide, $\mathrm{PI}, \mathrm{a}$ non permeant intercalating red probe), as previously described. ${ }^{8}$

Western blot analysis. Cultured cells were washed and scraped in PBS, then disrupted at $4^{\circ} \mathrm{C}$ in the extraction buffer $(20 \mathrm{mM}$ HEPES, $1 \mathrm{mM}$ EDTA, $1 \mathrm{mM}$ $\mathrm{Na}_{3} \mathrm{VO}_{4}, 250 \mathrm{mM}$ sucrose, $5 \mu \mathrm{M}$ digitonine, $1 \mathrm{mM}$ DTT, $1 \mathrm{mM}$ PMSF) for 15 to $30 \mathrm{~min}$ on ice. After 2 cycles of clarification at $2500 \times g$ for $5 \mathrm{~min}$, supernatant was centrifuged at $12000 \times \mathrm{g}$ for $15 \mathrm{~min}$ (Beckman Optima) and used for western-blot experiments. Alternatively, cytosol was separated from mitochondria. ${ }^{8}$

Human atherosclerotic tissue samples from carotid endarterectomy were homogenized in the extraction buffer, and used for SDS-PAGE either as total protein extracts or after immunoprecipitation experiments, then transferred onto nitrocellulose membranes, as previously described. ${ }^{8}$

Immunocytochemistry and immunohistochemistry. Cells grown on glass cover slides, were washed with PBS and fixed in cold methanol for $10 \mathrm{~min}$. After blocking with PBS containing $3 \% \mathrm{BSA}$ for $30 \mathrm{~min}$, cells were incubated with the indicated antibodies in PBS for $1 \mathrm{~h}$ and revealed with Alexa Fluor-conjugated secondary antibody for $1 \mathrm{~h}$. The slides (mounted in Vectashield mounting medium) were visualized using a Zeiss LSM 510 fluorescence confocal microscope.

Immunofluorescence detection of apoptotic cells was performed using the antisSDNA/APOSTAIN kit under the conditions given by the manufacturer (Abcys, Paris, France), and based on the increased sensitivity of DNA in apoptotic cells to thermal denaturation. Briefly, cells grown on glass cover slides, were washed with PBS and fixed in cold methanol for $10 \mathrm{~min}$. then incubated in $0.25 \mathrm{ml}$ formamide and heated to $75^{\circ} \mathrm{C}$ for $10 \mathrm{~min}$. At the end, $2 \mathrm{ml}$ of $1 \%$ non-fat dry milk in PBS were added for $15 \mathrm{~min}$, then the cells were washed in PBS and incubated with the anti single-stranded DNA monoclonal antibody (F7-26, Abcys), then with a fluoresceinconjugated anti-mouse antibody. Counterstaining of nuclei was performed with the DNA fluorochrome DAPI (Sigma).

Paraffin sections of human atherosclerotic carotid samples were incubated with the different antibodies, anti-ORP150 (1/50e). Immunostains were visualized by using avidin-biotin horseradish peroxidase system (Vectastain, ABC kit Elite, Vector Laboratories).

Cytosolic calcium evaluation. Cells were incubated for $15 \mathrm{~min}$ at $37^{\circ} \mathrm{C}$ in culture medium buffered with $20 \mathrm{mmol} / \mathrm{l} \mathrm{Hepes}$ and containing $0.5 \%$ bovine serum albumin and fluo-3/AM ( $5 \mu \mathrm{mol} / \mathrm{l})$. After dilution and incubation for $45 \mathrm{~min}$, cells were washed two times in PBS and their fluorescence was recorded (495 and $525 \mathrm{~nm}$ excitation and emission wavelength respectively). Results were normalized on a protein basis and expressed as percentage of control, as reported. ${ }^{24}$

Determination of enzyme activities. Cells were lysed in ice-cold $10 \mathrm{mM}$ Tris- $\mathrm{HCl}$ buffer $\mathrm{pH} 7.4$ and enzyme activities were determined using fluorogenic substrates. Calpain activity was determined using the Suc-Leu-Tyr-AMC substrate, and caspase activity was determined using the fluorogenic substrate Ac-DEVDAMC, under the previously used conditions. ${ }^{8}$
Alternatively, caspase activation was visualized using the in situ caspase detection kit FLICA ${ }^{\mathrm{TM}}$ under the conditions given by the manufacturer (Abcys, Paris, France).

Statistical analysis. The data are given as means \pm S.E.M. of three to six separate experiments. Estimates of statistical significance were performed by Anova (Tukey test, SigmaStat software). $P<0.05$ was considered to be statistically significant.

Acknowledgements. We acknowledge the financial support by INSERM, ANR (LiSA project ANR-05-PCOD-019-01), and University Toulouse-3. Marie Sanson was recipient of a fellowship from GRRC (Groupe de Réflexion sur la Recherche Cardio-Vasculaire). We thank Ms MH Grazide and C Bernis for their excellent technical assistance.

1. Lusis AJ. Atherosclerosis. Nature 2000; 407: 233-241.

2. Ross R. Atherosclerosis-an inflammatory disease. N Engl J Med 1999; 340: 115-126.

3. Dimmeler S, Hermann C, Zeiher AM. Apoptosis of endothelial cells. Contribution to the pathophysiology of atherosclerosis? Eur Cytokine Netw 1998; 9: 697-698.

4. Mallat Z, Tedgui A. Apoptosis in the vasculature: mechanisms and functional importance. Br J Pharmacol 2000; 130: 947-962.

5. Colles SM, Maxson JM, Carlson SG, Chisolm GM. Oxidized LDL-induced injury and apoptosis in atherosclerosis. Potential roles for oxysterols. Trends Cardiovasc Med 2001; 11: $131-138$

6. Salvayre R, Auge N, Benoist $\mathrm{H}$, Nègre-Salvayre A. Oxidized low-density lipoproteininduced apoptosis. Biochim Biophys Acta 2002; 1585: 213-221.

7. Escargueil-Blanc I, Salvayre R, Nègre-Salvayre A. Necrosis and apoptosis induced by oxidized low-density lipoproteins occur through two calcium-dependent pathways in ymphoblastoid cells. FASEB J 1994; 8: 1075-1080.

8. Vindis C, Elbaz M, Escargueil-Blanc I, Auge N, Heniquez A, Thiers JC et al. Two distinct calcium-dependent mitochondrial pathways are involved in oxidized LDL-induced apoptosis. Arterioscler Thromb Vasc Biol 2005; 25: 639-645.

9. Napoli C. Oxidation of LDL, atherogenesis, and apoptosis. Ann N Y Acad Sci 2003; 1010: 698-709.

10. Li D, Yang B, Mehta JL. Ox-LDL induces apoptosis in human coronary artery endothelial cells: role of PKC PTK, bcl-2, and Fas. Am J Physiol 1998; 275: H568-H576.

11. Sata M, Walsh K. Oxidized LDL activates fas-mediated endothelial cell apoptosis. J Clin Invest 1998; 102: 1682-1689.

12. Walter DH, Haendeler J, Galle J, Zeiher AM, Dimmeler S. Cyclosporin A inhibits apoptosis of human endothelial cells by preventing release of cytochrome $c$ from mitochondria Circulation 1998; 98: 1153-1157.

13. Porn-Ares MI, Saido TC, Andersson T, Ares MP. Oxidized low-density lipoprotein induces calpain-dependent cell death and ubiquitination of caspase 3 in HMEC-1 endothelial cells. Biochem J 2003; 374: 403-411.

14. Ikeda J, Kaneda S, Kuwabara K, Ogawa S, Kobayashi T, Matsumoto M et al. Cloning and expression of cDNA encoding the human $150 \mathrm{kDa}$ oxygen-regulated protein, ORP150. Biochem Biophys Res Commun 1997; 230: 94-99.

15. Kuwabara K, Matsumoto M, Ikeda J, Hori O, Ogawa S, Maeda $Y$ et al. Purification and characterization of a novel stress protein, the $150-\mathrm{kDa}$ oxygen-regulated protein (ORP150), from cultured rat astrocytes and its expression in ischemic mouse brain. J Biol Chem 1996; 271: 5025-5032.

16. Ozawa K, Kuwabara K, Tamatani M, Takatsuji K, Tsukamoto Y, Kaneda S et al. 150-kDa oxygen-regulated protein (ORP150) suppresses hypoxia-induced apoptotic cell death. J Biol Chem 1999; 274: 6397-6404.

17. Bando Y, Tsukamoto Y, Katayama T, Ozawa K, Kitao Y, Hori O et al. ORP150/HSP12A protects renal tubular epithelium from ischemia-induced cell death. FASEB J 2004; 18 : 1401-1403.

18. Tamatani M, Matsuyama T, Yamaguchi A, Mitsuda N, Tsukamoto $\mathrm{Y}$, Taniguchi M et al. ORP150 protects against hypoxia/ischemia-induced neuronal death. Nat Med 2001; 7 317-323

19. Kitao Y, Ozawa K, Miyazaki M, Tamatani M, Kobayashi T, Yanagi H et al. Expression of the endoplasmic reticulum molecular chaperone (ORP150) rescues hippocampal neurons from glutamate toxicity. J Clin Invest 2001; 108: 1439-1450.

20. Miyazaki M, Ozawa K, Hori O, Kitao Y, Matsushita K, Ogawa S et al. Expression of 150-kd oxygen-regulated protein in the hippocampus suppresses delayed neuronal cell death. $J$ Cereb Blood Flow Metab 2002; 22: 979-987.

21. Aleshin AN, Sawa Y, Kitagawa-Sakakida S, Bando Y, Ono M, Memon IA et al. 150-kDa oxygen-regulated protein attenuates myocardial ischemia-reperfusion injury in rat heart J Mol Cell Cardiol 2005; 38: 517-525.

22. Kobayashi T, Yura T, Yanagi H. The increment of anti-ORP150 autoantibody in initial stages of atheroma in high-fat diet fed mice. J Vet Med Sci 2002; 64: 177-180.

23. Tsukamoto Y, Kuwabara K, Hirota S, Ikeda J, Stern D, Yanagi H et al. 150-kD oxygenregulated protein is expressed in human atherosclerotic plaques and allows mononuclear 
phagocytes to withstand cellular stress on exposure to hypoxia and modified low-density lipoprotein. J Clin Invest 1996; 98: 1930-1941.

24. Maziere C, Morliere $\mathrm{P}$, Massy $\mathrm{Z}$, Kamel S, Louandre $\mathrm{C}$, Conte MA et al. Oxidized low-density lipoprotein elicits an intracellular calcium rise and increases the binding activity of the transcription factor NFAT. Free Radic Biol Med 2005; 38 472-480.

25. Orrenius S, Zhivotovsky B, Nicotera P. Regulation of cell death: the calcium-apoptosis link. Nat Rev Mol Cell Biol 2003; 4: 552-565.

26. Namba T, Hoshino T, Tanaka K, Tsutsumi S, Ishihara T, Mima S et al. Upregulation of 150 $\mathrm{kDa}$ oxygen-regulated protein by celecoxib in human gastric carcinoma cells. $\mathrm{Mol}$ Pharmacol 2007; 71: 860-870.

27. Wells KE, Alexander JJ, Miguel R. Calcium-dependent second-messenger regulation of low-density lipoprotein oxidation by human aortic smooth muscle cells. Surgery 1996; 120 337-344

28. Kitao Y, Hashimoto K, Matsuyama T, Iso H, Tamatani T, Hori O et al. ORP150/HSP12A regulates Purkinje cell survival: a role for endoplasmic reticulum stress in cerebellar development. J Neurosci 2004; 24: 1486-1496.

29. Feng B, Yao PM, Li Y, Devlin CM, Zhang D, Harding HP et al. The endoplasmic reticulum is the site of cholesterol-induced cytotoxicity in macrophages. Nat Cell Biol 2003; 5: 781-792.

30. Devries-Seimon T, Li Y, Yao PM, Stone E, Wang Y, Davis RJ et al. Cholesterol-induced macrophage apoptosis requires ER stress pathways and engagement of the type $A$ scavenger receptor. J Cell Biol 2005; 171: 61-73.

31. Pedruzzi E, Guichard C, Ollivier V, Driss F, Fay M, Prunet $C$ et al. NAD(P)H oxidase Nox-4 mediates 7-ketocholesterol-induced endoplasmic reticulum stress and apoptosis in human aortic smooth muscle cells. Mol Cell Biol 2004; 24: 10703-10717.
32. Nègre-Salvayre A, Fitoussi G, Troly M, Salvayre R. Comparative cytoprotective effect of dihydropyridine calcium channel blockers against the toxicity of oxidized low-density lipoprotein for cultured lymphoid cells. Biochem Pharmacol 1992; 44: 2379-2386.

33. Hanson CJ, Bootman MD, Roderick HL. Cell signalling: IP3 receptors channel calcium into cell death. Curr Biol 2004; 14: R933-R935.

34. Tiruppathi C, Ahmmed GU, Vogel SM, Malik AB. Ca2+ signaling, TRP channels, and endothelial permeability. Microcirculation 2006; 13: 693-708.

35. Lievremont JP, Rizzuto R, Hendershot L, Meldolesi J. BiP, a major chaperone protein of the endoplasmic reticulum lumen, plays a direct and important role in the storage of the rapidly exchanging pool of Ca2+. J Biol Chem 1997; 272: 30873-30879.

36. Bando Y, Katayama T, Kasai K, Taniguchi M, Tamatani M, Tohyama M. GRP94 (94 kDa glucose-regulated protein) suppresses ischemic neuronal cell death against ischemia/ reperfusion injury. Eur J Neurosci 2003; 18: 829-840.

37. Naved AF, Ozawa M, Yu S, Miyauchi T, Muramatsu H, Muramatsu T. CBP-140, a novel endoplasmic reticulum resident $\mathrm{Ca}(2+)$-binding protein with a carboxy-terminal NDEL sequence showed partial homology with $70-\mathrm{kDa}$ heat shock protein (hsp70). Cell Struct Funct 1995; 20: 133-141.

38. Szabadkai G, Bianchi K, Varnai P, De Stefani D, Wieckowski MR, Cavagna D et al. Chaperone-mediated coupling of endoplasmic reticulum and mitochondrial $\mathrm{Ca} 2+$ channels. J Cell Biol 2006; 175: 901-911.

39. Yla-Herttuala S, Palinski W, Rosenfeld ME, Parthasarathy S, Carew TE, Butler S et al. Evidence for the presence of oxidatively modified low-density lipoprotein in atherosclerotic lesions of rabbit and man. J Clin Invest 1989; 84: 1086-1095.

40. Bando Y, Ogawa S, Yamauchi A, Kuwabara K, Ozawa K, Hori O et al. 150-kDa oxygenregulated protein (ORP150) functions as a novel molecular chaperone in MDCK cells. Am J Physiol Cell Physiol 2000; 278: C1172-C1182. 